\title{
The Effect of Patient and Surgical Factors on Opioid Prescription Requests Following Arthroscopic Rotator Cuff Repair
}

\author{
Mathangi Sridharan, B.S., Richard Samade, M.D., Ph.D., Kyle J. Kopechek, B.S., \\ Austin J. Roebke, M.D., Kanu S. Goyal, M.D., Grant L. Jones, M.D., Julie Y. Bishop, M.D., \\ and Gregory L. Cvetanovich, M.D.
}

\begin{abstract}
Purpose: To determine whether differences in total morphine equivalent doses (MEDs) prescribed after arthroscopic rotator cuff repair (RCR) existed because of age younger than or older than 55 years and sex and to characterize potential risk factors for needing an opioid medication refill, visiting a provider other than the surgeon (either in the emergency department or ambulatory settings), and postoperative pain control requiring opioids approximately 6 weeks from the date of surgery. Methods: A retrospective cohort study of 100 patients who underwent arthroscopic RCR between July l, 2018 , to November 30,2018, in a single institution was performed. Data including demographics, perioperative treatments, and postoperative opioid prescriptions were recorded. Our primary hypotheses were evaluated with the WilcoxonMann-Whitney test. Univariate and multivariate analyses assessed potential risk factors for the 3 outcomes of interest. Results were given in adjusted odds ratios (aORs), 95\% confidence intervals (CIs), and $P$ values. Results: There was a difference $(P=.038)$ in total MEDs used (in $5 \mathrm{mg}$ oxycodone tablets) between males (median 56 tablets; interquartile range, 50-98 tablets) and females (median 78 tablets; interquartile range, 56-116 tablets). Age younger than 55 years was a risk factor for seeking an opioid refill $(\mathrm{OR}=2.51 ; \mathrm{CI}, 1.11-5.66 ; P=.026)$. A significant risk factor for visiting another provider was preoperative opiate use $(\mathrm{OR}=15.0 ; \mathrm{CI}, 1.79-125.8 ; P=.013)$. Age younger than than 55 years $(\mathrm{aOR}=2.51$; CI, 1.01-6.02; $P=.047)$, body mass index $(\mathrm{aOR}=1.08 ; \mathrm{CI}, 1.01-1.17 ; P=.046)$, and shorter surgical duration $(\mathrm{aOR}=$ 0.97; CI, 0.95-0.99, $P=.007$ ) were independent predictive factors for requiring opioids for pain control 6 weeks after surgery. Conclusions: After arthroscopic RCR, MED prescription is higher for females than males. The risk factors for requesting opioid prescription refill for pain control 6 weeks after surgery were age younger than 55 years and shorter surgical duration. Level of Evidence: Level III, retrospective comparative study.
\end{abstract}

$\mathbf{R}$ otator cuff repair (RCR), especially arthroscopic procedures, has steadily become a more common

From the College of Medicine, The Ohio State University Wexner Medical Center, Columbus, Ohio, U.S.A. (M.S., K.J.K.); and the Department of Orthopaedics, The Ohio State University Wexner Medical Center, Columbus, Ohio, U.S.A. (R.S., A.J.R., K.S.G, G.L.J., J.Y.B., G.L.C.).

The authors report no conflicts of interest in the authorship and publication of this article. Full ICMJE author disclosure forms are available for this article online, as supplementary material.

Received September 13, 2020; accepted January 15, 2021.

Address correspondence to Gregory Cvetanovich, M.D., Department of Orthopaedic Surgery, The Jameson Crane Sports Institute of The Ohio State University Wexner Medical Center, 2835 Fred Taylor Drive, Columbus, $\mathrm{OH}$ 43202,U.S.A.E-mail: gregory.cvetanovich@osumc.edu

(C) 2021 THE AUTHORS. Published by Elsevier Inc. on behalf of the Arthroscopy Association of North America. This is an open access article under the CC BY-NC-ND license (http://creativecommons.org/licenses/by-nc-nd/4.0/).

2666-061X/201566

https://doi.org/10.1016/j.asmr.2021.01.008 procedure in the United States, from the late $1990 \mathrm{~s}^{1}$ and mid $2000 \mathrm{~s}^{2}$ to the current decade $^{3}$ and has increasingly been performed on an outpatient basis. ${ }^{4}$ Although adequate pain control is an integral component to postoperative care after arthroscopic RCR, the rise in RCRs has been parallel with increased opioidrelated drug deaths between 1999 to $2014 .^{5-7}$ An estimated 2 million people suffer from opioid use disorder directly related to increasing amounts of opioid prescriptions ${ }^{6}$; in combination with underlying behavioral disorders, this can lead to persistent opioid use after many surgical procedures. ${ }^{8}$ In addition, patients frequently use less than the prescribed amount of opioids after their associated operation, ${ }^{9,10}$ which can pose risks for unintended uses. ${ }^{11}$ Orthopaedic surgeons in particular prescribe the third largest total of opioids among all providers. ${ }^{12}$ As a result, national guidelines have been formulated to reduce opiate medication 
prescriptions, ${ }^{13}$ and orthopaedic surgeons have investigated interventions such as preoperative counseling to curb opioid consumption. ${ }^{14,15}$

Although arthroscopic RCR can lead to improvements in patient-reported and functional motion in patients using opioids before surgery, these have been less than those seen in opiate-naïve patients. ${ }^{16,17}$ In addition, it has been found that opiate-tolerant patients had higher proportions of female sex, chronic pain disorders, and psychiatric conditions compared to opiate-naïve patients. ${ }^{16,18}$ For arthroplasty of the shoulder, in contrast to arthroscopy, preoperative opioid medication usage has been associated with higher postoperative opiate requirements and reduced functional outcome scores after anatomic ${ }^{19}$ and reverse total shoulder arthroplasty. ${ }^{20}$ For patients undergoing elective shoulder arthroplasty, age $<60$ years and long-term opioid use were found to be risk factors for increased opioid use after surgery. ${ }^{21}$ Based on studies that have consistently illustrated potential patient risk factors for increased opiate requirements, the current study aimed to determine whether these patient- and surgical-based risk factors, specifically age and sex, were generalizable to a patient population undergoing arthroscopic RCR. Such an evaluation could aid useful preoperative counseling by surgeons.

In this article, we describe a retrospective cohort study with the objective of elucidating risk factors for increased postoperative opioid consumption after arthroscopic RCR. The purposes of this study were to determine whether differences in total morphine equivalent doses (MEDs) prescribed after arthroscopic RCR existed because of age younger than or older than 55 years and sex and to characterize potential risk factors for needing an opioid medication refill, visiting a provider other than the surgeon (either in the emergency department or ambulatory settings), and postoperative pain control requiring opioids approximately 6 weeks from the date of surgery. We tested 2 null hypotheses: (1) postoperative opioid requirements after arthroscopic RCR, in MEDs, are not significantly different between patients younger than or older than 55 years of age and (2) postoperative MEDs are not significantly different between male and female patients.

\section{Methods}

\section{Study Population}

After obtaining Institutional Review Board study approval, 1 study author (M.S.) identified 114 patients treated in a single institution by 1 of 4 fellowshiptrained shoulder surgeons from July 1, 2018, to November 1, 2018. Inclusion criteria for patients consists of age older than 18 years and undergoing primary arthroscopic RCR. Exclusion criteria included active cancer diagnosis requiring baseline opioid prescription, prisoner status, additional operations within 42 days of RCR, open RCR, revision RCR, superior capsular reconstruction, or concomitant fracture fixation. These criteria led to 14 patients being eliminated, and a final number of $\mathrm{N}=100$ patients underwent further review of their electronic medical records in this retrospective cohort study. In our institution, 375 MEDs of opioids, the equivalent of 50 tablets of oxycodone, were routinely prescribed for patients on the day of surgery. An a priori power analysis was performed, and because no minimum clinically important difference (MCID) has been defined for MEDs consumed after arthroscopic RCR, we determined the MCID to be 83 MEDs for our primary null hypotheses. This corresponds to 11 doses of oxycodone $5 \mathrm{mg}$ tablets or just over 2 tablets of oxycodone consumed every 4 hours at 5 timepoints in 1 day. We selected this MCID after discussion with our physician assistant (PA-Cs) and surgeon staff who determined, from their experience, that more than 1 additional day of unanticipated opiate consumption was commonly the threshold that prompted patients to begin seeking additional aid after surgery. Assuming a standard deviation of 165 MEDs used after arthroscopic RCR (as found in the study by Klein et al. ${ }^{22}$ ) in the group with a mean 1 MCID higher than our baseline group, our study was found to have $80 \%$ power with an alpha level of 0.05 for our sample size. All opioid dosages were first converted into MEDs (thus facilitating direct comparison between multiple opioid medications) and then equivalents of oxycodone $5 \mathrm{mg}$ tablets to facilitate clinical interpretation of results.

\section{Data Collection and Perioperative Protocol}

From electronic medical record review, demographics including age, sex, body mass index (BMI), insurance type, employment status, and distance traveled to the site of surgery were collected. In addition, potentially influential behavioral qualities such as smoking status, alcohol abuse, marijuana drug use, intravenous drug use, baseline opioid use defined as having an active prescription for opioids within 3 months of surgery, a diagnosis of fibromyalgia, and a documented history of a mental health disorder were noted. Preoperative steroid injections and duration of symptoms were also recorded. Perioperative data, such as concomitant procedures (e.g., biceps tenodesis), tear thickness (partial versus full), length of surgery, and medications prescribed at discharge (including opiate MEDs) were also collected. Finally, outcomes such as the number and type of opioid refills, total MEDs prescribed, opioid use beyond 42 days after surgery, emergency department or alternative physician visits for additional opioid, a call or visit to the surgeon's office for opioid refills, and pain control requiring opioids at 2 weeks and 6 weeks after surgery were assessed. 
Table 1. Summary of Patient Demographics and Behavioral Characteristics

\begin{tabular}{|c|c|}
\hline Variable & All Study Patients $(N=100)$ \\
\hline$\overline{\text { Age (years) }}$ & $54.8 \pm 10.7$ \\
\hline Sex (number of females) & $37(37.0 \%)$ \\
\hline BMI $\left(\mathrm{kg} / \mathrm{m}^{2}\right)$ & $31.3 \pm 6.2$ \\
\hline $\begin{array}{l}\text { Insurance Type (private } \\
\text { insurance) }\end{array}$ & $43(43.0 \%)$ \\
\hline $\begin{array}{l}\text { Insurance Type (Medicare or } \\
\text { Medicaid insurance) }\end{array}$ & $42(42.0 \%)$ \\
\hline $\begin{array}{l}\text { Insurance Type (Workers' } \\
\text { Compensation) }\end{array}$ & $10(10.0 \%)$ \\
\hline Insurance Type (uninsured) & $5(5.0 \%)$ \\
\hline $\begin{array}{l}\text { Employment Status (currently } \\
\text { employed) }\end{array}$ & $61(61.0 \%)$ \\
\hline $\begin{array}{l}\text { Distance Traveled to Surgery } \\
\text { (miles) }\end{array}$ & $17.6(11.3-44.1)$ \\
\hline Diagnosis of Fibromyalgia & $2(2.0 \%)$ \\
\hline $\begin{array}{l}\text { Smoking Status (actively } \\
\text { smoking) }\end{array}$ & $18(18.0 \%)$ \\
\hline $\begin{array}{l}\text { Marijuana Use Status (actively } \\
\text { using) }\end{array}$ & $6(6.00 \%)$ \\
\hline $\begin{array}{l}\text { Alcohol Abuse Status (actively } \\
\text { using) }\end{array}$ & $5(5.00 \%)$ \\
\hline IVDU Status (actively using) & $0(0.00 \%)$ \\
\hline $\begin{array}{l}\text { Mental Health History Status } \\
\text { (active diagnosis) }\end{array}$ & $38(38.0 \%)$ \\
\hline $\begin{array}{l}\text { Preoperative Opioid Use Status } \\
\text { (using within } 3 \text { months) }\end{array}$ & $8(8.00 \%)$ \\
\hline \multicolumn{2}{|c|}{$\begin{array}{l}\text { NOTE. Demographic and pertinent behavioral data of all patients in } \\
\text { the study who underwent arthroscopic rotator cuff repair }(N=100 \\
\text { patients) are presented. Mean } \pm \text { standard deviation are provided for } \\
\text { normal variables, number and proportion are given for categorical } \\
\text { variables, and median and interquartile range (IQR) are shown for } \\
\text { non-normal interval data. }\end{array}$} \\
\hline
\end{tabular}

All surgeons involved in the study performed arthroscopic RCRs in the beach chair position, using 4 portals (posterior, lateral, anterior, and accessory anterolateral). In addition, all patients received general anesthetic and an interscalene regional anesthetic block to the operative extremity using a single injection. No patients had a catheter placed for analgesic infusion. Patients were immobilized in a sling after surgery, and motion was progressed by physical therapists using a standard protocol. Initial opioid prescriptions were given by 1 of 3 PA-Cs or a resident physician using a standard protocol. All requests for refills were completed only through these 3 PA-Cs.

\section{Documentation of Opiate Prescriptions}

This investigation was performed in a state that has a comprehensive pharmacy database: the Ohio Automatic Rx Reporting System. We used the Ohio Automatic Rx Reporting System to accurately determine the amount and type of opioids prescribed for each patient by any licensed provider in the state. To reiterate, clinical interpretation of results was facilitated by converting all opioid dosages to MEDs and then equivalents of oxycodone $5 \mathrm{mg}$ tablets, allowing for direct comparison between multiple opioid medications. Patients who requested refills on opioid prescription were prescribed $210 \mathrm{mg}$ of MEDs, equivalent to 28 tablets of oxycodone $5 \mathrm{mg}$.

\section{Statistical Analysis}

Statistical analyses were performed with standard software (Stata, version 15.0; StataCorp, College Station, TX). Descriptive statistics included mean \pm standard deviation for normal interval data, median with interquartile range (IQR) for non-normal interval data, and counts with proportions for categorical data. The Wilcoxon-Mann-Whitney test was used to evaluate for differences in total opioid prescription required between (1) patients younger or older than age 55 years, which was previously observed to be close to the average age of patients requiring arthroscopic RCR in our institution, and (2) male or female patients. After these analyses, a series of univariate logistic models were used to assess the unadjusted associations between multiple patient and surgical factors with the outcomes of (1) needing an opioid refill, (2) visiting the emergency department or another provider, and (3) requiring opioids for pain control 6 weeks after surgery as reported by the patient. Variable logistic regression models were then used to determine independent predictors of the aforementioned outcomes. This was done by considering all factors in univariate analysis and then using a backward selection method with an exit criterion of $P>.05$. Model goodness of fit was confirmed with the Hosmer-Lemeshow test. ${ }^{23}$ The discriminatory capability of the multivariate models was summarized by the area under the receiver operator curve (AUROC); capability was defined as poor for AUROC <0.7, fair for 0.70-0.79, good for 0.80-0.89, and excellent for values $>0.90$. Results were summarized as odds ratios (ORs), 95\% confidence intervals (CIs), and $P$ values. The significance level was $P=.05$.

\section{Results}

\section{Demographics and Surgical Characteristics}

In the 100 enrolled patients, the mean age was $54.8 \pm 10.7$ years, $37.0 \%$ were female, the mean BMI was $31.3 \pm 6.2 \mathrm{~kg} /$ $\mathrm{m}^{2}, 43.0 \%$ had private insurance, $42 \%$ had Medicaid or Medicare insurance, 10\% had workers' compensation, 5\% were uninsured, and $61.0 \%$ were employed (Table 1). Moreover, $18.0 \%$ were actively smoking at the time of surgery, $38.0 \%$ had a preoperative diagnosis of a mental health disorder, and $8.00 \%$ were using opioids before surgery within 3 months of the surgical date.

By the day of surgery, patients had a median of 6 months (IQR, 4-14 months) of symptoms (Table 2). During surgery, $74.0 \%$ had a full-thickness tear, and nearly $90.0 \%$ of patients underwent subacromial 
Table 2. Summary of Preoperative Treatments, Perioperative Interventions, and Postoperative Opioid Use

\begin{tabular}{|c|c|}
\hline Variable & All Study Patients $(N=100)$ \\
\hline $\begin{array}{l}\text { Steroid Injections (number } \\
\text { received preoperatively) }\end{array}$ & $0(0-1)$ \\
\hline Duration of Symptoms (months) & $6(4-14)$ \\
\hline $\begin{array}{l}\text { Tear Thickness (number with full- } \\
\text { thickness tear) }\end{array}$ & $74(74.0 \%)$ \\
\hline $\begin{array}{l}\text { Distal Clavicle Excision Performed } \\
\text { (count) }\end{array}$ & $4(4.00 \%)$ \\
\hline $\begin{array}{l}\text { Biceps Tenodesis Performed } \\
\text { (count) }\end{array}$ & $90(90.0 \%)$ \\
\hline $\begin{array}{l}\text { Subacromial Decompression } \\
\text { Performed (count) }\end{array}$ & $86(86.0 \%)$ \\
\hline Duration of Surgery (minutes) & $86.0 \pm 22.2$ \\
\hline $\begin{array}{l}\text { Morphine Equivalent Doses at } \\
\text { Discharge (milligrams) }\end{array}$ & $375(375-420)$ \\
\hline $\begin{array}{l}\text { Patients Requiring a Refill } \\
\text { (number receiving) }\end{array}$ & $51(51.0 \%)$ \\
\hline $\begin{array}{l}\text { Morphine Equivalent Doses } \\
\text { Refilled (milligrams) }\end{array}$ & $90(0-375)$ \\
\hline $\begin{array}{l}\text { Morphine Equivalent Doses Given } \\
\text { in Total (milligrams) }\end{array}$ & $450(375-772.5)$ \\
\hline $\begin{array}{l}\text { Patients Seeing Another Provider } \\
\text { (number performing) }\end{array}$ & $4(4.00 \%)$ \\
\hline $\begin{array}{l}\text { Patients with Uncontrolled Pain } 2 \\
\text { Weeks Postoperatively (count) }\end{array}$ & $56(56.0 \%)$ \\
\hline $\begin{array}{l}\text { Patients with Uncontrolled Pain } 6 \\
\text { Weeks Postoperatively (count) }\end{array}$ & $58(58.0 \%)$ \\
\hline \multicolumn{2}{|c|}{$\begin{array}{l}\text { NOTE. Key data on preoperative symptoms duration, steroid in- } \\
\text { jections, characteristics of the arthroscopic rotator cuff repairs per- } \\
\text { formed, quantities of opioids prescribed, and pertinent patient } \\
\text { outcomes with regards to pain control for all individuals ( } \mathrm{N}=100 \\
\text { patients) are presented. Mean standard deviation are provided for } \\
\text { normal variables, number and proportion are given for categorical } \\
\text { variables, and median and interquartile range (IQR) are shown for } \\
\text { non-normal interval data. }\end{array}$} \\
\hline
\end{tabular}

decompression and biceps tenodesis. The mean duration of surgery was $86.0 \pm 22.2$ minutes. On discharge, unless a medical contraindication was present, all patients were given $100 \mathrm{mg}$ of gabapentin 3 times daily and a median of $375 \mathrm{mg}$ of MEDs (IQR, 375-420), equivalent to 50 tablets of oxycodone $5 \mathrm{mg}$. Although no patients were prescribed nonsteroidal anti-inflammatory drugs or acetaminophen at discharge, all patients were recommended to take ibuprofen or acetaminophen for pain control, unless contraindicated by medical history or allergies. It was found that $51.0 \%$ of patients required a refill of opioids, for a median of $450 \mathrm{mg}$ of MEDs (IQR, 375$772.5)$ prescribed by 6 weeks after surgery. There were 4 patients who saw another provider for opioid refills, and $58.0 \%$ of patients did not feel that their pain was adequately controlled without the need for opioids at the 6-week postoperative visit.

\section{Comparison of Opioid Use by Age and Sex}

With regard to our primary hypotheses (Fig 1A), no significant difference existed $(P=.071)$ between total postoperative opioid prescription after arthroscopic
RCR in patients older than 55 years (median 60 tablets; IQR, 50-92 tablets) than those younger than 55 years (median 84 tablets; IQR, 50-113 tablets). When comparing by sex (Fig 1B), females received more opioid prescriptions (median 78 tablets; IQR, 56-116 tablets) than males (median 56 tablets; IQR, 50-98 tablets) and this difference was significant $(P=.038)$.

\section{Unadjusted Risk Factors for Outcomes of Interest}

It was found that age younger than 55 years was an unadjusted risk factor for seeking an opioid refill $(\mathrm{OR}=$ 2.51; CI, 1.11-5.66; $P=.026)$. An unadjusted significant risk factor for visiting another provider for opioid refills was preoperative opiate use within 3 months of surgery $(\mathrm{OR}=15.0 ; \mathrm{CI}, 1.79-125.8 ; P=.013)$. Significant risk factors for requiring opioids for pain control 6 weeks after surgery were age younger than 55 years $(\mathrm{OR}=2.56$; $\mathrm{CI}, 1.11-5.89 ; P=.027)$, higher BMI $(\mathrm{OR}=$ 1.08; CI, 1.01-1.16; $P=.042)$, and shorter surgical duration $(\mathrm{OR}=0.97$; $\mathrm{CI}, 0.95-0.99 ; P=.007)$.

\section{Independent Risk Factors for Outcomes of Interest}

No significant risk factors were identified for needing a refill or visiting another provider in multivariate analysis. Age younger than 55 years $(\mathrm{aOR}=2.5 \mathrm{l}$; $\mathrm{CI}$, 1.01-6.02; $P=.047$ ), BMI (aOR = 1.08; CI, 1.01-1.17; $P=.046)$, and shorter length of surgery $(\mathrm{aOR}=0.97$, CI, 0.95-0.99; $P=.007$ ) were independent predictive factors for requiring opioid prescriptions for pain control 6 weeks after surgery. This model had fair ability $($ AUROC $=0.73)$ to predict this outcome (Fig 2).

\section{Discussion}

Previous investigations have explored potential associations with postoperative opioid consumption and outcomes after lumbar spinal fusion, ${ }^{24}$ total hip and knee arthroplasty, ${ }^{24,25}$ anatomic total shoulder arthroplasty, ${ }^{19}$ and reverse total shoulder arthroplasty, ${ }^{20}$ with a focus on preoperative opioid consumption. Using the Kaiser Permanente Shoulder Arthroplasty Registry, Rao et al. ${ }^{21}$ found that age younger than 60 years, sex, race, BMI, American Society of Anesthesiologists classification, and preoperative opioid use were patient-based risk factors for increased opioid use within 1 year of shoulder arthroplasty. In relation to arthroscopic RCR, risk factors that have been suggested as heightening patients' need for postoperative opiates include preoperative opioid use, ${ }^{16,17}$ psychiatric distress, ${ }^{22,26}$ myalgia, ${ }^{18}$ and low back pain. ${ }^{18}$ Given that different arthroscopic shoulder procedures have shown differential rates of prolonged postoperative opioid use, ${ }^{27}$ our investigation sought to confirm the role of age and sex on opioid prescription needs after surgery and secondarily determine the patient- and procedural-based risk factors for suboptimal patient-reported pain control. 

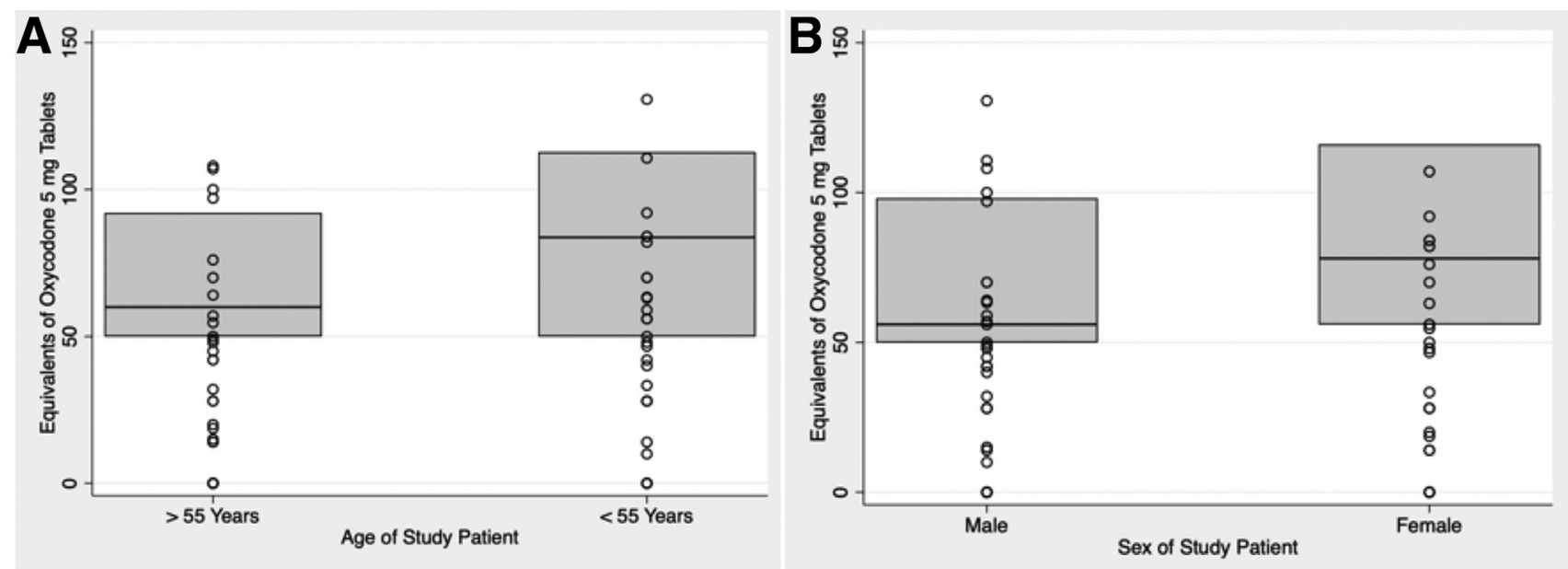

Fig 1. Combination box and scatter plots comparing total opioids prescribed to patients after arthroscopic rotator cuff repair (in equivalents of 5 milligram (mg) tablets of oxycodone) on the basis of (A) age less than or greater than 55 years of age and (B) male or female sex. For equivalents of $5 \mathrm{mg}$ tablets of oxycodone, the cumulative morphine equivalent dose was calculated for each patient and divide by the conversion ratio of $5 \mathrm{mg}$ of oxycodone for every $7.5 \mathrm{mg}$ of morphine. In the box plots, the lower box boundary represented the first quartile, the interior line represented the median, and the upper box boundary represented the third quartile.

With attention to our study hypothesis, we were unable to reject our first null hypothesis that there was no difference in total postoperative opioid prescription between patients younger than 55 years of age and those patients older than 55 years of age. However, we were able to reject our second null hypothesis that there was no difference in total postoperative opioid prescription between male and female patients. Our findings with regard to age differed from our pre-study alternative hypothesis that younger age would be a risk factor for increased MEDs after surgery, as suggested by other researchers. ${ }^{21,28}$ Further evaluation of the ageMED association would be useful and warranted in future prospective and retrospective studies with a different patient sample to confirm or refute this finding. Given that younger age was found to be independently associated with a greater level of pain 6 weeks after surgery, it is possible that younger patients have a higher level of perceived pain; however, the current study is underpowered to detect such an association. As for our finding for sex-related differences, this is congruent with data from other studies of postoperative opioid use after shoulder operations. ${ }^{16,21} \mathrm{~A}$ possible explanation for this finding could be attributed to differences in preoperative expectations and coping mechanisms for pain after surgery between males and females. Subsequent research to better elucidate the causative issues for this sex-based difference and tailor appropriate interventions would be warranted to further explore our finding.

Our analyses for risk factors for our first outcome of interest, the need for a refill of opioid medications, did not reveal any significant factors. Similar to our aforementioned data regarding no significant differences with regard to age groups with postoperative MEDs, future investigations with different cohorts of patients would be useful to verify this conclusion. We recommend particular attention in these studies toward risk factors described in the literature, such as sex,

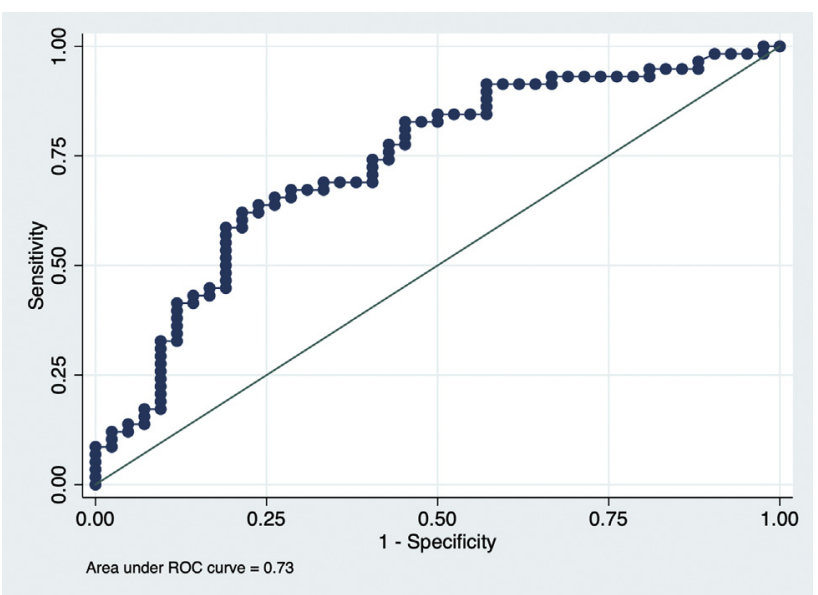

Fig 2. Summary of the predictive ability of a multiple logistic model for the outcome of requiring opioids for pain control at the time of the 6-week postoperative visit after arthroscopic rotator cuff repair (RCR). The three model predictors were (1) patient age in years less than or greater than 55 years (as a binary variable), body mass index (as a continuous variable), and (3) duration of the surgical procedure in minutes (as a continuous variable). The area under the receiver operative characteristic curve of 0.73 indicated fair ability for the model to predict the outcome. 
preoperative opioid use, and a history of a mental health disorder.

One strength of our study is the elucidation of independent risk factors for the outcomes of (1) visiting a provider other than the surgeon for pain control and (2) requiring opioids for pain control by the time of the 6-week postoperative visit. Our first logistic regression model highlighted the significant association between preoperative opioid usage and the outcome of needing to visit a provider other than the surgeon. In other studies, preoperative opioid use has been shown to adversely impact clinical outcomes and postoperative opioid requirements after RCR. ${ }^{16-18}$

In a similar vein, we were able to construct another logistic regression model that illustrated the significant associations between (1) patient age younger than 55 years, (2) BMI, and (3) shorter procedure duration with patient-reported requirement of opioids for pain control 6 weeks after RCR. As described earlier, younger age and BMI have been found to be risk factors for increased postoperative opioid consumption ${ }^{21,28}$; thus these findings are congruent with the current literature. As for shorter procedure duration, controlling for the presence or absence of concomitant procedures (such as distal clavicle excision and biceps tenodesis) revealed that they were not significant confounding factors. Notably, structural characteristics that define the severity of rotator cuff tears are not correlated with pain levels after repair. ${ }^{29,30}$ Potential explanations for the association with shorter surgical duration could include reduced time spent in debridement of inflammatory torn rotator cuff before RCR, guidance on postoperative expectations for relatively smaller operations, or decreased physical therapy for less-intensive procedures. Future investigations controlling for these variables could be useful. Taken together, the clinical significance of these models could help improve preoperative counseling and postoperative guidance for patients at risk for increased opioid requirements after arthroscopic RCR.

\section{Limitations}

Our investigation has several limitations. For example, no standardized preoperative and postoperative assessments of pain, such as the Visual Analog Scale, and function, such as Disabilities of the Arm, Shoulder, and Hand and American Shoulder Elbow Surgeons Standardized Form were routinely available for all patients in the study. This is an inherent drawback of the retrospective nature of the study and limits precise quantification of pain reduction from preoperative levels and its variation as time from surgery progressed. It also limits comparisons of functional outcomes with those reported in the literature. Future investigations would ideally collect Visual Analog Scale, Disabilities of the Arm, Shoulder, and Hand, American
Shoulder Elbow Surgeons and other functional assessments at multiple timepoints, before and after surgery. Another limitation of the study was a lack of standardization of a script for preoperative counseling, as well as systematic tracking of actual opioid pills consumed. Thus the specific quantity of opioids consumed by patients was not documented per se, but the amount of opioid prescription requested was known. Furthermore, patients were recommended to take nonopioid pain medications as needed after surgery, but the consumption of such medications and their effect on pain control could not be measured. In addition, multimodal pain management with agents such as gabapentin, nonsteroidal anti-inflammatory drugs, and acetaminophen, has been demonstrated to reduce narcotic pain consumption. ${ }^{31}$ Ideally, standardization of preoperative and postoperative measurement and counseling of opioid usage, in the setting of a prospective randomized controlled trial, would help control for potential cofounders, and this could be a future research direction. Finally, our study interval of interest was up to the 6-week postoperative time point and may have benefited from longer follow-up (e.g., 1 year) for more detailed assessment of functional assessments. However, we selected the 6-week timepoint because this represents the end of surgeon-driven opioid prescribing, per our institution's policy.

\section{Conclusions}

After arthroscopic RCR, MED prescription is higher for females than males. The risk factors for requesting opioid prescription refill for pain control 6 weeks after surgery were age younger than 55 years and shorter surgical duration.

\section{References}

1. Colvin A, Egorova N, Harrison A, Moskowitz A, Flatow E. National trends in rotator cuff repair. J Bone Joint Surg Am 2012;94:227-233.

2. Zhang A, Montgomery S, Ngo S, Hame S, Wang J, Gamradt S. Analysis of rotator cuff repair trends in a large private insurance population. Arthroscopy 2013;29: 623-629.

3. Day M, Westermann R, Bedard N, Glass N, Wolf B. Trends associated with open versus arthroscopic rotator cuff repair. HSS J 2019;15:133-136.

4. Iyengar J, Samagh S, Schairer W, Singh G, Valone Fr, Feeley B. Current trends in rotator cuff repair: Surgical technique, setting, and cost. Arthroscopy 2014;30:284-288.

5. Rudd R, Seth P, David F, Scholl L. Increases in drug and opioid-involved overdose deaths-United States, 2010 2015. MMWR Morb Mortal Wkly Rep 2016;65:1445-1452.

6. Schuchat A, Houry D, Guy GJ. New data on opioid use and prescribing in the United States. JAMA 2017;318: 425-426. 
7. Soelberg C, Brown RJ, Du Vivier D, Meyer J, Ramachandran B. The US opioid crisis: Current federal and state legal issues. Anesth Analg 2017;125:1675-1681.

8. Brummett C, Waljee J, Goesling J, et al. New persistent opioid use after minor and major surgical procedures in US adults. JAMA Surg 2017;152:e170504.

9. Bicket M, Long J, Pronovost P, Alexander G, Wu C. Prescription opioid analgesics commonly unused after surgery: A systematic review. JAMA Surg 2017;152: 1066-1071.

10. Jamieson M, Everhart J, Lin J, Jain S, Awan H, Goyal K. Reduction of opioid use after upper-extremity surgery through a predictive pain calculator and comprehensive pain plan. J Hand Surg Am 2019;44:1050-1059.

11. Bartels K, Mayes L, Dingmann C, Bullard K, Hopfer C, Binswanger I. Opioid use and storage patterns by patients after hospital discharge following surgery. PLoS One 2016;11:e0147972.

12. Morris B, Mir H. The opioid epidemic: Impact on orthopaedic surgery. J Am Acad Orthop Surg 2015;23:267-271.

13. Frieden T, Houry D. Reducing the risks of relief-The CDC Opioid-Prescribing Guideline. N Engl J Med 2016;374: $1501-1504$.

14. Holman J, Stoddard G, Horwitz D, Higgins T. The effect of preoperative counseling on duration of postoperative opiate use in orthopaedic trauma surgery: A surgeonbased comparative cohort study. J Orthop Trauma 2014;28:502-506.

15. Syed U, Aleem A, Wowkanech C, et al. Neer Award 2018: the effect of preoperative education on opioid consumption in patients undergoing arthroscopic rotator cuff repair: A prospective, randomized clinical trial. J Shoulder Elbow Surg 2018:27:962-967.

16. Williams B, Redlich N, Mickschl D, Grindel S. Influence of preoperative opioid use on postoperative outcomes and opioid use after arthroscopic rotator cuff repair. J Shoulder Elbow Surg 2019;28:453-460.

17. Sabesan V, Petersen-Fitts G, Sweet M, Katz D, Lima D, Whaley J. The impact of preoperative opioid use on outcomes after arthroscopic rotator cuff repair. JSES Open Access 2018;2:155-158.

18. Westermann R, Anthony C, Bedard N, et al. Opioid consumption after rotator cuff repair. Arthroscopy 2017;33: 1467-1472.

19. Morris B, Sciascia A, Jacobs C, Edwards T. Preoperative opioid use associated with worse outcomes after anatomic shoulder arthroplasty. J Shoulder Elbow Surg 2016;25: 619-623.
20. Morris B, Laughlin M, Elkousy H, Gartsman G, Edwards T. Preoperative opioid use and outcomes after reverse shoulder arthroplasty. J Shoulder Elbow Surg 2015;24:11-16.

21. Rao A, Chan P, Prentice H, et al. Risk factors for postoperative opioid use after elective shoulder arthroplasty. J Shoulder Elbow Surg 2018;27:1960-1968.

22. Klein J, Davis D, Wells Z, et al. The Distress and Risk Assessment Method predicts postoperative narcotic use in patients undergoing rotator cuff repair. J Shoulder Elbow Surg 2019;28:S146-S153.

23. Hosmer D Jr, Lemeshow S, Sturdivant R. Applied logistic regression. Hoboken, NJ: John Wiley \& Sons, 2013.

24. Jain N, Brock J, Malik A, Phillips F, Khan S. Prediction of complications, readmission, and revision surgery based on duration of preoperative opioid use: Analysis of major joint replacement and lumbar fusion. J Bone Joint Surg Am 2019;101:384-391.

25. Smith S, Bido J, Collins J, Yang H, Katz J, Losina E. Impact of preoperative opioid use on total knee arthroplasty outcomes. J Bone Joint Surg Am 2017;99:803-808.

26. Potter M, Wylie J, Greis P, Burks R, Tashjian R. Psychological distress negatively affects self-assessment of shoulder function in patients with rotator cuff tears. Clin Orthop Relat Res 2014;472:3926-3932.

27. Gil J, Gunaseelan V, DeFroda S, Brummett C, Bedi A, Waljee J. Risk of prolonged opioid use among opioidnaïve patients after common shoulder arthroscopy procedures. Am J Sports Med 2019;47:1043-1050.

28. Han H, Kass P, Wilsey B, Li C. Age, gender, and earlier opioid requirement associations with the rate of dose escalation in long-term opioid therapy. J Opioid Manag 2013;9:129-138.

29. Dunn W, Kuhn J, Sanders R, et al. Symptoms of pain do not correlate with rotator cuff tear severity: a crosssectional study of 393 patients with a symptomatic atraumatic full-thickness rotator cuff tear. J Bone Joint Surg Am 2014;96:793-800.

30. Ravindra A, Barlow J, Jones G, Bishop J. A prospective evaluation of predictors of pain after arthroscopic rotator cuff repair: psychosocial factors have a stronger association than structural factors. J Shoulder Elbow Surg 2018;27: 1824-1829.

31. McLaughlin DC, Cheah JW, Aleshi P, Zhang AL, Ma CB, Feeley BT. Multimodal analgesia decreases opioid consumption after shoulder arthroplasty: a prospective cohort study. J Shoulder Elbow Surg 2018;27:686-691. 